\title{
Liquid Ammoniates as Efficient Electrolytes for Room-Temperature Rechargeable Sodium-Metal Batteries Based on an Organic Cathode
}

\author{
Débora Ruiz-Martínez, Teresa Lana-Villarreal, and Roberto Gómez* \\ Cite This: ACS Appl. Energy Mater. 2021, 4, 6806-6814 \\ Read Online
}

ABSTRACT: The development of room-temperature rechargeable sodium-metal batteries (SMBs) has gathered enormous interest as they are an attractive option to develop cost-effective devices to store energy from renewable sources. However, one of their main constraints is the high reactivity of sodium with most of the electrolytes commonly employed, which hampers finding an optimized SMB configuration. Here, we describe the use of a highly concentrated electrolyte based on liquid ammonia and sodium iodide. Its formulation is $\mathrm{NaI} \cdot 3.3 \mathrm{NH}_{3}$, and it confers metallic sodium high stability at room temperature. Moreover, the electrolyte is significantly more cost-effective than typical organic or ionic liquid electrolytes. Here, the advantages of this electrolyte are shown in a battery based on the combination of sodium metal as an anode and poly(anthraquinonyl sulfide) (PAQS) as a cathode. This combination leads to an experimental capacity of $218 \mathrm{~mA} \cdot \mathrm{h} \cdot \mathrm{g}^{-1}$ at 5C (reaching $97 \%$ of the theoretical capacity) at room temperature and maintains a

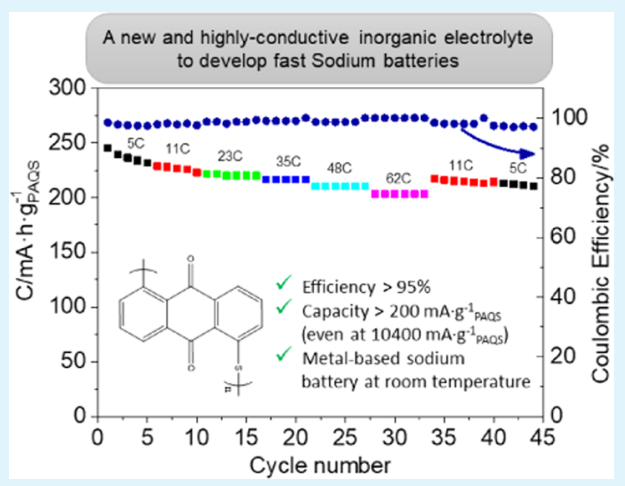
Coulombic efficiency close to $100 \%$ over 300 cycles. In addition, the system described here attains, after 100 cycles, specific energies over $320 \mathrm{~W} \cdot \mathrm{h} \cdot \mathrm{kg}_{\mathrm{PAQS}}{ }^{-1}$ and a specific power of $3500 \mathrm{~W} \cdot \mathrm{kg}_{\mathrm{PAQS}}{ }^{-1}$, with an energy efficiency over $90 \%$. These metrics, which compare favorably with those of typical organic electrolytes, are linked to an extremely low value of the charge-transfer resistance at the cathode/ammoniate interphase. Despite the dissolution of PAQS during the reduction process, the battery already presents a capacity retention over $80 \%$ after 150 cycles at $5 \mathrm{C}$.

KEYWORDS: sodium-metal batteries, room temperature, organic cathode, poly(anthraquinonyl sulfide), highly concentrated electrolytes, ammoniates

\section{INTRODUCTION}

Probably one of the main challenges of the 21 st century derives from both the extensive implementation of renewable energy technologies and their intermittent nature. These renewable resources are continuously subjected to irregular fluctuations, which need to be dealt with when the demand surpasses the supply or vice versa. Energy-storage devices can leverage renewable sources by (i) smoothing power output, (ii) time shifting the generated energy to follow the demand, and (iii) mitigating power quality issues. In the last years, researchers have investigated different energy-storage solutions. Among all of the proposed systems, batteries are particularly attractive due to their high energy efficiency and low maintenance. ${ }^{1}$

Sodium batteries (SBs) have been extensively studied as a clear alternative to their lithium counterparts, both alkaline metals presenting similar physicochemical properties. SBs are expected to find application mainly in large-scale energy storage, hybrid vehicles, and renewable power stations. Due to the natural abundance of sodium, the resulting devices are more cost-effective than lithium ones. ${ }^{2-5}$ It is worth noting that some types of sodium-metal batteries (SMBs) have already been commercialized, such as $\mathrm{Na}-\mathrm{S}$ and ZEBRA batteries. However, they operate at high temperatures $\left(300{ }^{\circ} \mathrm{C}\right.$ or higher), implying safety hazards. The development of practical low-temperature $\mathrm{SBs}$ is considered as an urgent outstanding challenge. ${ }^{6}$

One of the key aspects for the fabrication of roomtemperature SBs is the development of reversible, highcapacity, and low-cost cathodic materials. Nowadays, the most representative cathode materials for SBs are based on inorganic compounds containing transition metals in their formulation. These materials are commonly prepared through high-energy consumption procedures and they present a relatively low theoretical capacity. In addition, the sodium insertion kinetics tends to be slow. ${ }^{7-15}$ In this context, organic compounds have become promising alternative materials for SB cathodes. A theoretical capacity typically higher than those of inorganic compounds and the possibility of exhibiting multielectron redox reactions should be underlined as their

Received: March 29, 2021

Accepted: June 15, 2021

Published: June 25, 2021 
most relevant properties. Furthermore, organic materials are easily compatible with green chemistry methodologies as they can be obtained from natural sources and their synthesis does not imply a high-energy consumption. ${ }^{16-23}$

Among the organic compounds, carbonyl-containing molecules have attracted considerable attention in the last 40 years. They are characterized by a high capacity and by a fast redox kinetics. The $\mathrm{C}=\mathrm{O}$ groups can be reduced to form alcoholates $\left(\mathrm{C}-\mathrm{O}^{-} \mathrm{X}^{+}, \mathrm{X}^{+}\right.$being a cation, for instance, $\left.\mathrm{Na}^{+}\right)$, which can be reoxidized to the carbonyl form upon charging. ${ }^{24-27}$ Unfortunately, the electrodes based on these compounds suffer from a fast capacity fading upon cycling due to their high solubility in organic solvents. In addition, they present a low conductivity, which often results in poor electrochemical performance. Several strategies have been tested to improve their electrochemical performance. Polymerization or immobilization of the organic molecules in porous media such as porous carbon, carbon nanotubes (NTs), graphene, or even metaorganic frameworks has been successfully employed. The host structure offers effective pathways for electron transport, improving the electrode conductivity and also the stability against dissolution. ${ }^{28-33}$

Poly(anthraquinonyl sulfide) (PAQS) is a well-known carbonyl polymer that has been characterized as a highperformance cathode for rechargeable batteries. It shows a reversible electrochemical behavior, with a high theoretical capacity of $225 \mathrm{~mA} \cdot \mathrm{h} \cdot \mathrm{g}^{-1}$ (Scheme 1). ${ }^{34,35}$ Based on the

Scheme 1. On the Left-Hand Side: Chemical Structure of PAQS; On the Right-Hand Side: Sodiated PAQS
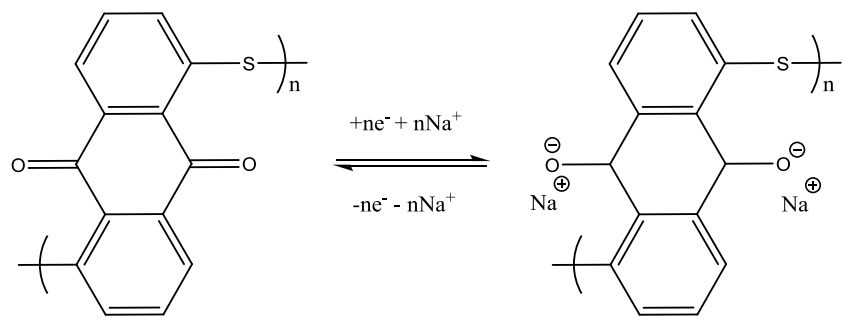

flexible frameworks of PAQS, it is expected that the cathode can reversibly accommodate a large density of $\mathrm{Na}$ ions without much swelling, achieving a fast kinetics for $\mathrm{Na}^{+}$insertion/ extraction.

On the other hand, the development of cost-effective electrolytes is another priority for the practical implementation of SBs. Several formulations have been proposed over the last years aiming at the optimization of the electrolyte properties. They include different salts and solvents as well as ionic liquids. In this context, highly concentrated electrolytes have been proposed to develop rechargeable batteries. There is a consensus that these electrolytes may allow a higher chargedischarge rate performance. In addition, they can stabilize the metal alkaline plating-stripping, avoiding a dendritic growth. However, high viscosities and slow ion diffusion are their main shortcomings. ${ }^{36-38}$

The inorganic electrolyte represented by the formula $\mathrm{NaI}$. $3.3 \mathrm{NH}_{3}$ is scarcely studied despite its potential technoeconomic advantages. It was described for the first time by BadozLambling and co-workers in 1988 for its use in primary batteries. ${ }^{39}$ Among the most interesting properties of $\mathrm{NaI}$. $3.3 \mathrm{NH}_{3}$, we find its high sodium ion concentration $(7.6 \mathrm{M})$, which provides a high specific conductivity at room temper- ature $\left(80 \mathrm{mS} \cdot \mathrm{cm}^{-1}\right)$. Even at temperatures as low as $4{ }^{\circ} \mathrm{C}$, the conductivity is well above $50 \mathrm{mS} \cdot \mathrm{cm}^{-1}$. This is connected to the fact that, despite its high salt content, this ammoniate shows a relatively low viscosity $(9.04 \mathrm{mPa} \cdot \mathrm{s}) \cdot{ }^{40,41}$ In addition, due to the large density of $\mathrm{Na}$ ions in the electrolyte, depletion of sodium near the electrode surface is not expected even at high $\mathrm{C}$ rates. On the other hand, the ammonia-based electrolyte has low flammability, and it is at least 3 times more cost-effective than common organic and ionic liquid electrolytes described in the battery context. All of these properties favor the use of $\mathrm{NaI} \cdot 3.3 \mathrm{NH}_{3}$ as a promising electrolyte for SMBs.

In this work, we show for the first time that the combination of PAQS and sodium metal with an unconventional inorganic electrolyte based on liquid ammonia leads to a novel lowtemperature and high-performance rechargeable sodium-metal battery. The resulting cost-effective battery possesses a superior rate performance, with a specific capacity of at least $200 \mathrm{~mA} \cdot \mathrm{h} \cdot \mathrm{g}^{-1}$ even at rates as high as 62C (10 $400 \mathrm{~mA}$. $\mathrm{g}_{\mathrm{PAQS}}{ }^{-1}$ ) and a specific power above $3500 \mathrm{~W} \cdot \mathrm{kg}_{\mathrm{PAQS}}{ }^{-1}$ at $20^{\circ} \mathrm{C}$, which compares favorably with systems based on the typical organic electrolytes.

\section{EXPERIMENTAL SECTION}

PAQS Synthesis. PAQS was synthesized by a polycondensation reaction between anhydrous $\mathrm{Na}_{2} \mathrm{~S}$ and 1,5-dichloroanthraquinone (96\%, Sigma Aldrich). ${ }^{34}$ First, $\mathrm{Na}_{2} \mathrm{~S} \cdot x \mathrm{H}_{2} \mathrm{O}(7<x<9$, Sigma Aldrich) was dehydrated in a vacuum oven using a thermal treatment based on four consecutive steps: (1) $4 \mathrm{~h}$ at $50{ }^{\circ} \mathrm{C}$; (2) $4 \mathrm{~h}$ at $80{ }^{\circ} \mathrm{C}$; (3) $2 \mathrm{~h}$ at $120{ }^{\circ} \mathrm{C}$; and (4) $2 \mathrm{~h}$ at $160{ }^{\circ} \mathrm{C}$. A stoichiometric amount of $1,5-$ dichloroanthraquinone was then added to the anhydrous $\mathrm{Na}_{2} \mathrm{~S}$ in $\mathrm{N}$ methyl-2-pyrrolidone (NMP). The mixture was refluxed at $150{ }^{\circ} \mathrm{C}$ for $10 \mathrm{~h}$ under magnetic stirring. After the reaction was completed, the solid was filtered and washed with plenty of deionized water and acetone. The product was dried in a vacuum oven at $150{ }^{\circ} \mathrm{C}$ overnight. Finally, the PAQS particles were mechanically treated in a ball mill at $100 \mathrm{rpm}$ for $3 \mathrm{~h}$ to reduce their initial size. Such a low spin rate was selected to avoid melting the PAQS particles. Further details about the mechanical treatment are included in the Supporting Information (SI).

Preparation of the PAQS-Based Cathodes. A homogeneous powder was prepared by mixing a dry mixture of $60 \mathrm{wt} \%$ PAQS powder, $30 \mathrm{wt} \%$ carbon nanotubes (NTs) (multiwalled, L 6-9 nm, $95 \%$, Sigma Aldrich) as a conductive additive, and 10 wt \% poly(tetrafluoroethylene) (PTFE) as a binder in a ball mill at 350 rpm for $1 \mathrm{~h}$. Subsequently, $4 \mathrm{mg}$ of this powder was placed on a substrate area of $1 \mathrm{~cm}^{2}$. A carbon-coated aluminum foil was used as a current collector (substrate). Adhesion of the active material was achieved by dry pressing, using a hydraulic press ( 1.5 ton for $2 \mathrm{~min}$ ). Finally, the electrodes were dried in a vacuum oven at $80{ }^{\circ} \mathrm{C}$ overnight prior to electrochemical characterization. Other electrode formulations were also assayed, using the same procedure described above, but changing the nature of the additive or the applied pressure. These modifications are detailed along the text and in the Supporting Information (SI).

Preparation of the Anthraquinone (AQ)-Based Cathodes. The electrochemical behavior of PAQS was compared to that of anthraquinone (AQ). The corresponding electrodes were composed of $\mathrm{AQ} / \mathrm{NTs} /$ poly(vinylidene fluoride) (PVDF) at ratios 60:30:10. Prior to electrode preparation, all of the components were mixed in a ball mill at $350 \mathrm{rpm}$ for $1 \mathrm{~h}$. Subsequently, the particles were dispersed in NMP. The electrodes were prepared by drop casting, using a carbon-covered aluminum foil as a substrate. They were dried at 100 ${ }^{\circ} \mathrm{C}$ in a vacuum oven overnight before their electrochemical characterization.

Physical Characterization. PAQS powder was characterized by attenuated total reflectance (ATR) Fourier transform infrared (FTIR) 

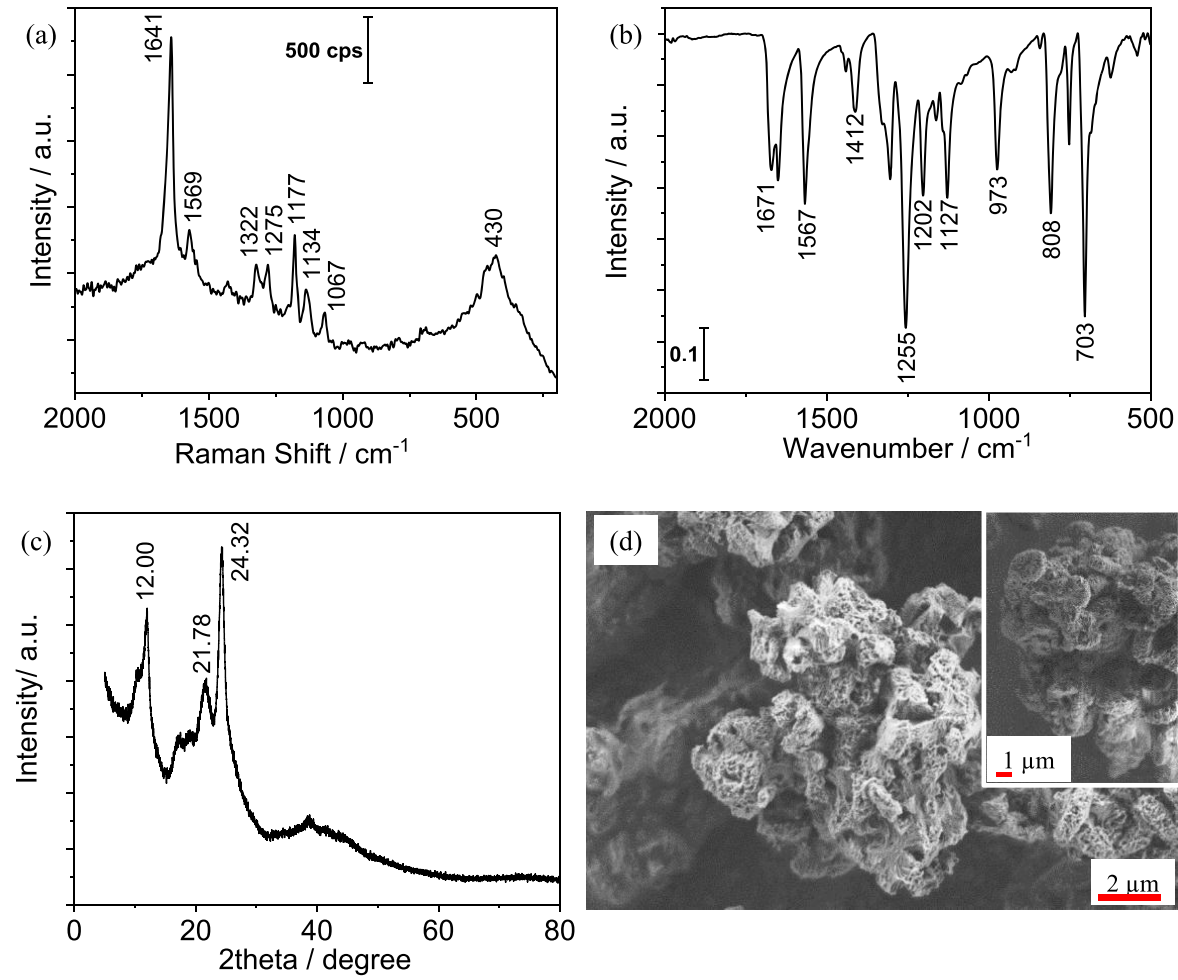

Figure 1. (a) Raman spectrum, (b) ATR FTIR spectrum, (c) XRD pattern, and (d) FESEM images for PAQS particles. The inset in (d) shows a detail of the PAQS rough surface.

spectroscopy (employing a BRUKER IFS 66/S spectrometer), Raman spectroscopy (using a JASCO NRS-5100 inverted confocal microscope coupled with a Nd:YAG laser $(534 \mathrm{~nm}))$, and X-ray diffraction (XRD) (with a Bruker D8-Advance diffractometer). The morphology of the active material was revealed by means of field-emission scanning electron microscopy (FESEM) (ZEISS, Merlin VP Compact coupled with an EDX system Bruker Quantax 400).

Electrochemical Measurements. Electrochemical experiments were performed in a two-electrode split cell using a Whatman 934-AH glass microfiber as a separator and a sodium-metal foil as an anode. The liquid ammoniate $\mathrm{NaI} \cdot 3.3 \mathrm{NH}_{3}$ was prepared and used as an electrolyte. $^{41}$ The cell was assembled in a nitrogen-filled glovebox with a concentration of oxygen and moisture below $5 \mathrm{ppm}$. Cyclic voltammograms were recorded at 5 and $20 \mathrm{mV} \cdot \mathrm{s}^{-1}$ from 1.2 to $2.6 \mathrm{~V}$ vs $\mathrm{Na}^{+} / \mathrm{Na}$. The galvanostatic charge-discharge measurements were performed at different currents (C rates) in such a voltage window. Electrochemical impedance spectroscopy (EIS) experiments were conducted from $100 \mathrm{kHz}$ to $10 \mathrm{mHz}$ using a perturbation amplitude of $\pm 10 \mathrm{mV}$ at $2.2 \mathrm{~V}$ vs $\mathrm{Na}^{+} / \mathrm{Na}$, which corresponds to the electrode open-circuit potential. All of the electrochemical measurements were carried out with an Origalys potentiostat-galvanostat (OGF-500) at room temperature.

\section{RESULTS AND DISCUSSION}

PAQS particles prepared by polycondensation were chemically and structurally characterized by XRD, FTIR, and Raman spectroscopy. Their morphology was studied by FESEM after a ball milling treatment at $100 \mathrm{rpm}$ for $3 \mathrm{~h}$. Figure 1a shows the Raman spectrum for PAQS after the fluorescence baseline correction. The wide peak observed at about $430 \mathrm{~cm}^{-1}$ can be assigned to a combination of out-of-plane ring deformations involving sulfur atoms ${ }^{42}$ in agreement with PAQS spectra previously reported. ${ }^{43}$ Other characteristic peaks appear at higher wavenumbers, which can be assigned to phenylenesulfur stretching modes $\left(1067\right.$ and $\left.1134 \mathrm{~cm}^{-1}\right)$, in-plane $\mathrm{C}-\mathrm{H}$ bending vibrations $\left(1177 \mathrm{~cm}^{-1}\right), \mathrm{C}-\mathrm{C}$ stretching modes $(1275$ and $\left.1322 \mathrm{~cm}^{-1}\right)$, symmetric stretching of sulfur-disubstituted ring $\left(1569 \mathrm{~cm}^{-1}\right)$, and $\mathrm{C}=\mathrm{O}$ stretching vibrations of the anthraquinonyl group $\left(1641 \mathrm{~cm}^{-1}\right) .^{42}$ Figure $1 \mathrm{~b}$ shows the FTIR-ATR spectrum for the as-synthesized PAQS. As observed, it matches well with those reported by other authors, confirming that PAQS has been properly synthesized. $^{43-47}$ The spectrum shows the stretching vibrations for the $\mathrm{C}=\mathrm{O}$ and $\mathrm{C}=\mathrm{C}$ bonds at 1671 and $1567 \mathrm{~cm}^{-1}$, respectively. In addition, the peaks at 1412 and $1127 \mathrm{~cm}^{-1}$ can be ascribed to sulfur-disubstituted aromatic ring and sulfurring stretching vibrations, respectively. Figure 1c shows the XRD pattern for PAQS. Three remarkable diffraction peaks clearly stand out at $12.00,21.78$, and, $24.32^{\circ}$, indicating a crystalline structure in agreement with the literature. ${ }^{47}$

As a conclusion, the XRD pattern and the FTIR and Raman spectra confirm the generation of PAQS by following the employed polycondensation methodology. ${ }^{43-47}$ In addition, Figures $1 \mathrm{~d}$ and S1 show a sponge-like structure for the as generated PAQS. As revealed by the inset of Figure $1 \mathrm{~d}$, the particles have a submicrometric structure that confers them a certain porosity degree. This morphology could be beneficial for the diffusion of large cations such as $\mathrm{Na}^{+}$, which could promote the battery performance.

The electrode components (active material, conductive carbon, and binder) were mechanically mixed in a planetary ball mill at $350 \mathrm{rpm}$ for $1 \mathrm{~h}$. The final powder structure is substantially different compared to that of the as-prepared PAQS, as displayed in Figure 2a. The PAQS particles become smaller and flatter, and they appear covered by carbon NTs. The electrodes were prepared by the dry-pressing technique applying 1.5 ton $\cdot \mathrm{cm}^{-2}$, which renders a homogeneous material distribution over the conducting substrate, as shown in Figure $2 b$. 


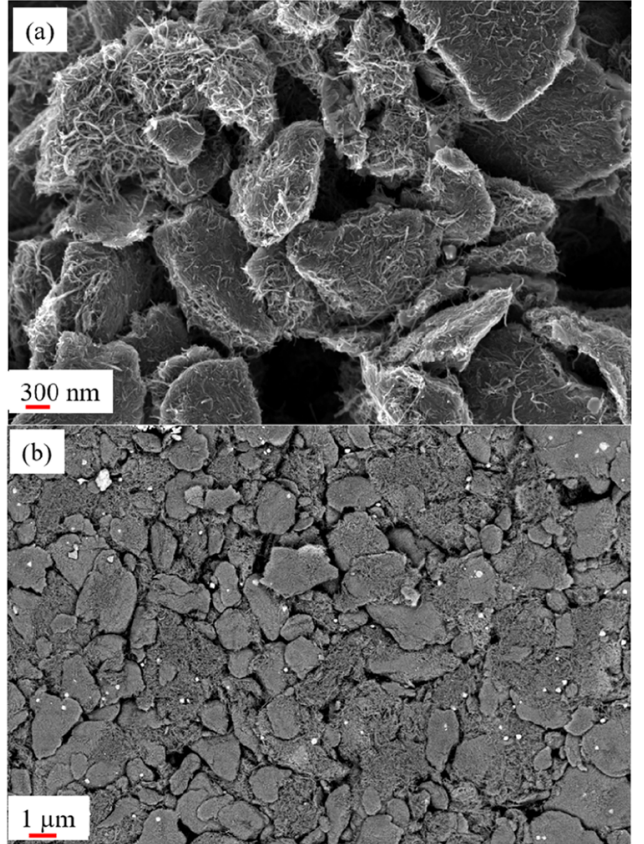

Figure 2. (a) FESEM image for PAQS/NTs/PTFE particles after the mechanical treatment at $350 \mathrm{rpm}$ in the ball mill and (b) FESEM for the final PAQS electrode surface.

The electrochemical characterization of the PAQS cathodes was carried out in a two-electrode split cell using $\mathrm{NaI} \cdot 3.3 \mathrm{NH}_{3}$ as an electrolyte and a sodium-metal piece as an anode. Figure 3 displays representative cyclic voltammograms at room

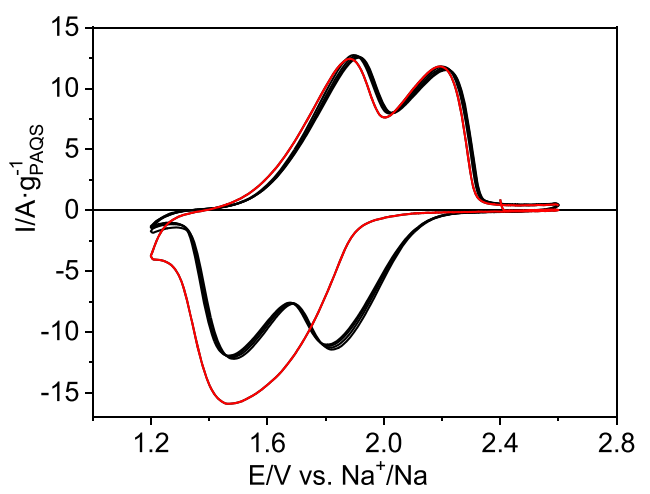

Figure 3. Cyclic voltammograms at $20 \mathrm{mV} \cdot \mathrm{s}^{-1}$ for a PAQS electrode in $\mathrm{NaI} \cdot 3.3 \mathrm{NH}_{3}$. The voltammogram drawn in red corresponds to the first cycles. Voltammograms drawn in black represent cycles from 2 to 5.

temperature for a PAQS electrode with the formulation PAQS/NTs/PTFE in proportions 60:30:10 at a mass loading of $4 \mathrm{mg} \cdot \mathrm{cm}^{-2}$. It shows a reversible electrochemical behavior due to the n-type redox activity of the anthraquinonyl groups of PAQS. ${ }^{34,48,49}$ There is a significant difference between the initial and subsequent scans. In this regard, when the cell is assembled, the open-circuit potential is $2.4 \mathrm{~V}$, indicating that PAQS is initially oxidized. The first cathodic scan (voltammogram drawn in red) only shows one reduction peak located at $1.45 \mathrm{~V}$ with a relatively large current, suggesting the existence of an activation process for PAQS reduction. This phenomenon has also been observed in previous studies. ${ }^{31,33-35,50-52}$ After the first activation cycle, two pairs of symmetric redox peaks are defined, located at $1.90 / 2.20 \mathrm{~V}$ in the positive-going scan and at $1.80 / 1.45 \mathrm{~V}$ in the negative-going scan. These peaks are characterized by similar currents and exchanged charges. They are separated by about $300 \mathrm{mV}$, indicating that the full sodiation process for PAQS occurs in two steps. This fact could be related with a large Coulombic or steric repulsion for the incorporation of the second $\mathrm{Na}^{+}$in each anthraquinone unit of the PAQS structure. ${ }^{34,51}$

To verify that the employed electrochemical window is adequate, a voltammetric study was carried out and it is presented in the SI (Figure S2). In summary, the positive potential limit was set at $2.6 \mathrm{~V}$ as the electrolyte starts to be oxidized from this potential, ${ }^{41}$ while the negative potential limit was sequentially varied toward less positive values. At potentials more negative than $1.2 \mathrm{~V}$ vs $\mathrm{Na}^{+} / \mathrm{Na}$, an abrupt and irreversible current appears. Simultaneously, the reversible behavior partly disappears, the two reversible redox processes of PAQS being barely distinguishable. This behavior suggests the possible irreversible breaking of the $S-S$ bonds. Accordingly, a potential of $1.2 \mathrm{~V}$ was chosen as the negative potential limit for the PAQS electrochemical characterization. Importantly, in the potential range between 1.2 and $2.6 \mathrm{~V}$, the capacity of the PAQS electrodes is close to its theoretical one. $^{34,43}$

In parallel, a comparative study of the electrochemical behavior of anthraquinone (AQ)-based electrodes in $\mathrm{NaI}$. $3.3 \mathrm{NH}_{3}$ was performed. As shown in Figure 4, AQ also shows two pairs of symmetric well-defined redox peaks, located at $1.90 / 2.30 \mathrm{~V}$ in the positive-going scan and at $1.75 / 1.35 \mathrm{~V}$ in the negative-going scan, as in the case of PAQS. However, there is a slight shift in the potentials of the redox peaks. This
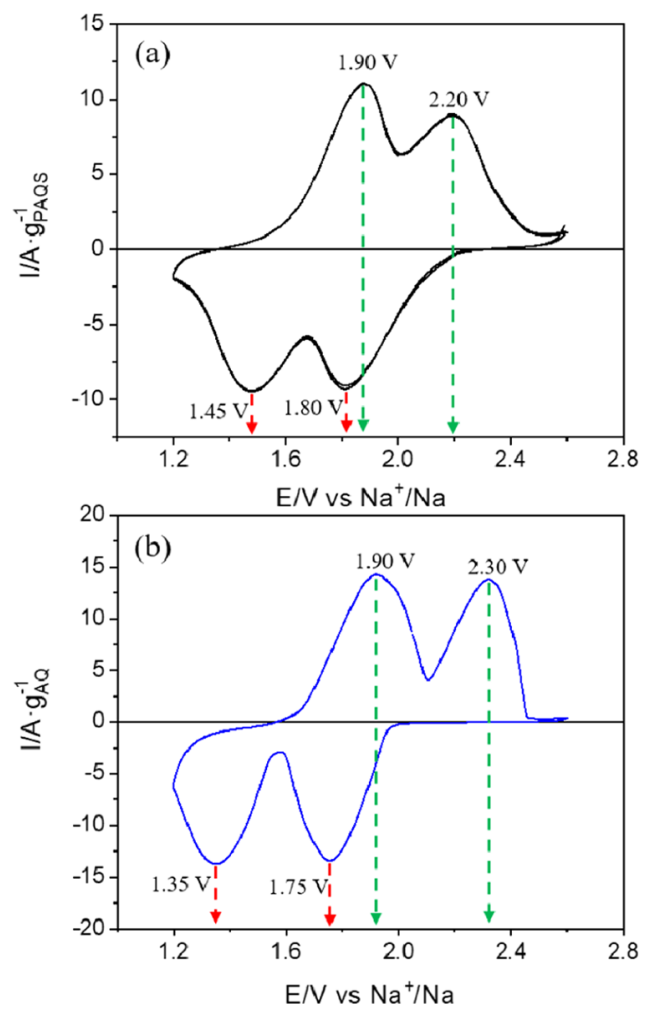

Figure 4. Cyclic voltammograms at $20 \mathrm{mV} \cdot \mathrm{s}^{-1}$ in $\mathrm{NaI} \cdot 3.3 \mathrm{NH}_{3}$ for: (a) $\mathrm{PAQS} / \mathrm{NTs} / \mathrm{PTFE}$ and (b) AQ/NTs/PVDF electrodes. In all cases, the ratio between the active material:conducting carbon:binder was 60:30:10. 
could be related to the fact that PAQS is a polymer. Note that PAQS is based on AQ units substituted in positions 4 and 9 to constitute a polymer with $S$ linkages. Such a configuration can modify the energy of the molecular orbitals, varying the potential at which the redox processes take place. ${ }^{20}$

PAQS also shows advantages in terms of reversibility and specific capacity in comparison to AQ. The difference between the first anodic peak and the first cathodic peak is $0.40 \mathrm{~V}$ for PAQS, while this difference is $0.55 \mathrm{~V}$ in the case of AQ. This is a good indication that the reversibility of the redox process is higher in the case of PAQS. Probably, the sulfur bridge connecting the anthraquinone units (present in PAQS) improves the kinetics of electron transfer from the electrolyte to the electrode and vice versa. ${ }^{48}$ On the other hand, the experimental specific capacity calculated from the voltammograms is similar for both electrodes, even if the theoretical capacity of AQ is higher than that of PAQS (290 vs $225 \mathrm{~mA} \cdot \mathrm{h}$. $\mathrm{g}^{-1}$ ). This could be related to the fact that the sulfur atoms present in PAQS could contribute to the final capacity of the electrode as previously suggested. ${ }^{43}$ However, we cannot completely discard the influence of other factors, such as the possibility that part of the AQ electrode is not electroactive.

To achieve the maximum performance with PAQS-based electrodes, their composition was optimized. Special attention was paid to (i) the ratio of the components (PAQS, conductive carbon, and binder) and the effect of the pressure applied during electrode preparation; (ii) the nature of the additives, both conductive carbon (NTs or carbon Super P) and a binder (PTFE or PVDF); and (iii) mass loading (4, 8, or $16 \mathrm{mg}$. $\mathrm{cm}^{-2}$ ). More details about the electrode formulation are given in the SI. The electrodes were characterized by cyclic voltammetry at $20 \mathrm{mV} \cdot \mathrm{s}^{-1}$ and $5 \mathrm{mV} \cdot \mathrm{s}^{-1}$ in $\mathrm{NaI} \cdot 3.3 \mathrm{NH}_{3}$. In all cases, the two redox processes of PAQS are observed (Figures S3-S5), although the peak intensity and reversibility depend on the electrode composition/preparation. Based on the electrochemical behavior, the formulation PAQS/NTs/ PTFE in proportions 60:30:10 prepared by the dry-pressing technique (applying $1.5 \mathrm{ton} \cdot \mathrm{cm}^{-2}$ for $2 \mathrm{~min}$ ) was chosen as the most appropriate.

Charge-discharge experiments were performed in a twoelectrode split cell using a sodium-metal piece as a negative electrode and $\mathrm{NaI} \cdot 3.3 \mathrm{NH}_{3}$ as an electrolyte. Figure 5 shows five charge-discharge cycles at $5 \mathrm{C}\left(2.5 \mathrm{~mA} \cdot \mathrm{cm}^{-2}\right.$ or $1300 \mathrm{~mA}$. $\left.\mathrm{g}_{\mathrm{PAQS}}{ }^{-1}\right)$. The curves are characterized by two plateaus associated to the peaks observed in the voltammograms. The

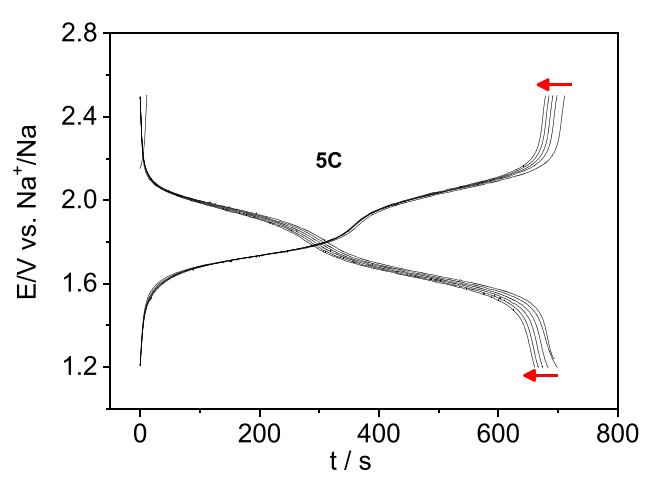

Figure 5. Charge-discharge curves for a PAQS electrode $\left(4 \mathrm{mg} \cdot \mathrm{cm}^{-2}\right.$ of mass loading) in $\mathrm{NaI} \cdot 3.3 \mathrm{NH}_{3}$ at $5 \mathrm{C}\left(2.5 \mathrm{~mA} \cdot \mathrm{cm}^{-2}\right)$. The experiments were carried out in a two-electrode split cell using sodium metal as an anode at room temperature. arrows show the evolution of the curves in successive cycles. From this figure, the calculated gravimetric capacity of the electrode is $202 \mathrm{~mA} \cdot \mathrm{h} \cdot \mathrm{g}_{\mathrm{PAQS}}{ }^{-1}$ and the Coulombic efficiency is virtually $100 \%$. The energy efficiency is above $90 \%$, which is notably higher than the values reported by analogous systems based on organic electrolytes at comparable C rates. ${ }^{18,53,54}$

Figure 6a shows the specific capacity for PAQS electrodes at different $\mathrm{C}$ rates. The PAQS electrode was submitted to three
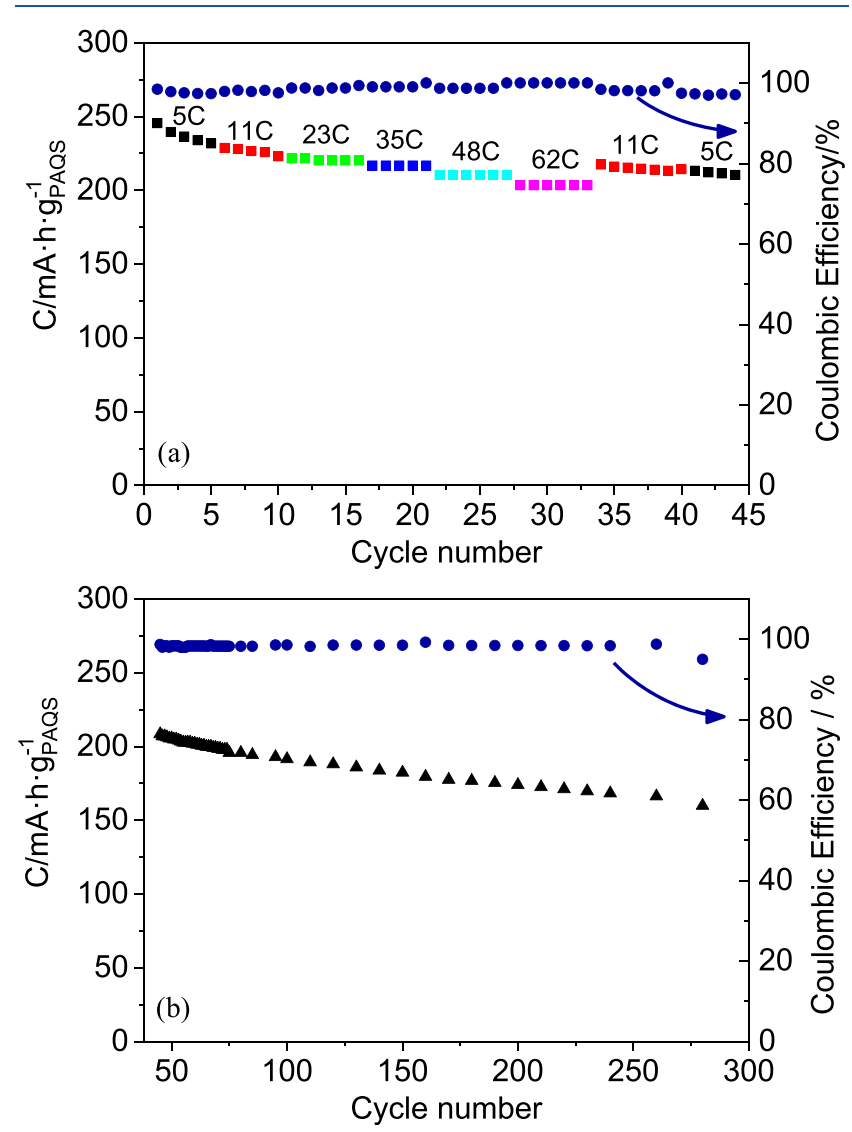

Figure 6. Charge-discharge experiments for a PAQS electrode (4 $\mathrm{mg} \cdot \mathrm{cm}^{-2}$ of mass loading) in $\mathrm{NaI} \cdot 3.3 \mathrm{NH}_{3}$. (a) Charge-discharge cycles at different $\mathrm{C}$ rates. (b) Cyclability for a PAQS electrode at 11C $\left(5 \mathrm{~mA} \cdot \mathrm{cm}^{-2}\right)$. The experiments were carried out at room temperature with the same PAQS electrode in a two-electrode split cell using sodium metal as an anode.

voltammetric cycles at $20 \mathrm{mV} \cdot \mathrm{s}^{-1}$ prior to galvanostatic measurements. The results indicate that, as expected, the maximum specific capacity of the electrode is reached at relatively slow $\mathrm{C}$ rates (5C). In addition, there is a progressive decrease in the electrode capacity with the number of cycles, which is mitigated when the $\mathrm{C}$ rate is extremely high (35C, $48 \mathrm{C}$, or $62 \mathrm{C}$ ). The cyclability was also studied using a constant $\mathrm{C}$ rate. As observed in Figure $6 \mathrm{~b}$, the electrode capacity decreases progressively with cycling at $11 \mathrm{C}$. To gain further insight into the capacity decay, cyclic voltammograms were acquired after a certain number of cycles (see Figure S6 in the SI). Their morphology significantly changes with cycling. From 0 charge-discharge cycle to cycle 300 , a diminution of the specific current was observed, accompanied by a loss in the definition of the redox processes. After the experiments, the separator showed a slight orange coloration, pointing to the dissolution of PAQS. Figure S7 shows an optical photograph of the split cell after the electrochemical characterization, 
including the separator, which acquires a yellowish-orange coloration. This observation can be related to the fact that the reduced form of PAQS $\left(\mathrm{Na}_{n} \mathrm{PAQS}\right)$ is slightly soluble in $\mathrm{NaI}$. $3.3 \mathrm{NH}_{3}$. In such a way, part of the active material would be lost in each cycle, consequently leading to a capacity decay. Concurrently, a loss of contact between the electrode and the substrate could also contribute to the observed capacity decay. In such a case, parts of the electrode would become electrically isolated with the number of cycles, inducing the observed capacity loss.

In any case, it is worth noting that PAQS electrodes in NaI$3.3 \mathrm{NH}_{3}$ can reach a specific capacity above $200 \mathrm{~mA} \cdot \mathrm{h} \cdot \mathrm{g}_{\mathrm{PAOS}}{ }^{-1}$ even at $\mathrm{C}$ rates as high as $62 \mathrm{C}\left(10400 \mathrm{~mA} \cdot \mathrm{g}_{\mathrm{PAOS}}{ }^{-1}\right)$. This promising result can be ascribed to the use of $\mathrm{NaI}$ ammoniate as an electrolyte in combination with the high inner surface area of the cathode particles (see the inset in Figure 1d). The specific energy and power for a PAQS electrode in the $\mathrm{NaI}$ ammoniate have been tentatively estimated, considering a conservative average specific capacity of $180 \mathrm{~mA} \cdot \mathrm{h} \cdot \mathrm{g}_{\mathrm{PAQS}}{ }^{-1}$, occurring after more than 100 cycles according to the experiment at $11 \mathrm{C}$ (Figure $6 \mathrm{~b}$ ). A value as high as $320 \mathrm{~W} \cdot \mathrm{h}$. $\mathrm{kg}_{\mathrm{PAQS}}{ }^{-1}$ is obtained for the specific energy, the specific power being around $3500 \mathrm{~W} \cdot \mathrm{kg}_{\mathrm{PAOS}}{ }^{-1}$. These values are comparable and even larger than those reported in the literature for analogous systems based on PAQS and organic sodium electrolytes for lower $\mathrm{C}$ rates and wider potential windows. ${ }^{17,34,43,47,55}$ The promising results obtained in this work are directly linked to the use of $\mathrm{NaI} \cdot 3.3 \mathrm{NH}_{3}$ as an electrolyte.

On the other hand, to validate the $\mathrm{Na}_{n} \mathrm{PAQS}$ solubility hypothesis, a PAQS electrode was chemically reduced by introducing an electrode in a solution containing $0.1 \mathrm{M} \mathrm{NaOH}$ in methanol and $0.2 \mathrm{M} \mathrm{NaBH}_{4}$. Immediately, a red-orange color appeared in the solution (see Figure S8 in SI). This result clearly indicates that reduced PAQS is soluble in polar solvents. In agreement, morphological changes can be observed in the electrode by SEM images (see Figure S9). The naked carbon NTs originally present at the electrode surface are no longer observed, pointing to the dissolution of PAQS during its electrochemical reduction and its redeposition on the carbon NTs during the subsequent oxidation process. At the same time, the edges of PAQS particles become ill-defined.

With the aim of increasing the stability of PAQS upon cycling, charge-discharge experiments were carried out for two mass loadings of $4 \mathrm{mg} \cdot \mathrm{cm}^{-2}$ and $8 \mathrm{mg} \cdot \mathrm{cm}^{-2}$ using the optimized composition described above (PAQS/NTs/PTFE in proportions 60:30:10). Figure 7 shows a comparison of the evolution of the specific capacity of both electrodes for 150 cycles at a constant rate of $5 \mathrm{C}$. The thinner electrode shows a specific capacity higher than that of the thicker one in the first cycles $\left(218 \mathrm{~mA} \cdot \mathrm{h} \cdot \mathrm{g}_{\mathrm{PAQS}}{ }^{-1}\right.$ vs $\left.184 \mathrm{~mA} \cdot \mathrm{h} \cdot \mathrm{g}_{\mathrm{PAQS}}{ }^{-1}\right)$. In both cases, the capacity decreases with the number of cycles due to the solubility of reduced PAQS, although the thicker electrode tends to stabilize. Probably, the effect of reduced PAQS dissolution is mitigated by the larger amount of PAQS present in the cathode. At the end of the experiment, the specific capacity is slightly larger for the high-loading electrode (145 $\mathrm{mA} \cdot \mathrm{h} \cdot \mathrm{g}_{\mathrm{PAQS}}{ }^{-1}$ vs $\left.138 \mathrm{~mA} \cdot \mathrm{h} \cdot \mathrm{g}_{\mathrm{PAQS}}{ }^{-1}\right)$. These results indicate that thicker electrodes of PAQS in the $\mathrm{NaI}$ liquid ammoniate do not only have a larger capacity, but they also stabilize the electrochemical behavior of PAQS upon cycling.

Finally, to further understand the electrochemical behavior of the system NallNaI-3.3 $\mathrm{NH}_{3}$ IIPAQS/NTs/PTFE (60:30:10)

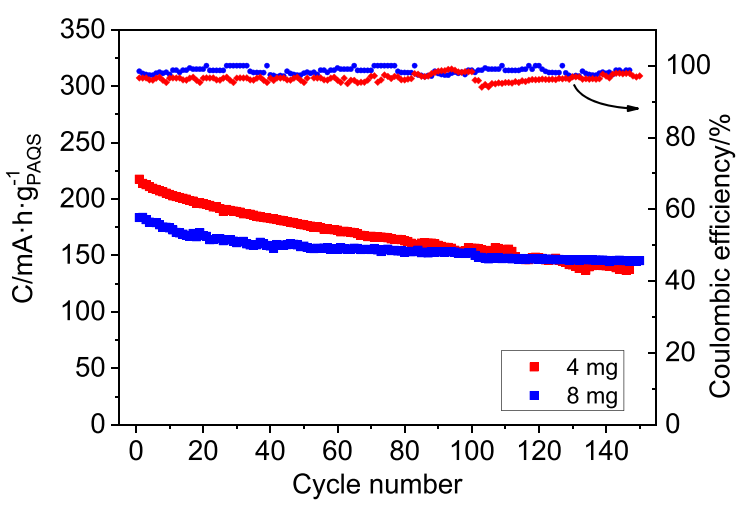

Figure 7. Specific capacity for PAQS electrodes of 4 and $8 \mathrm{mg} \cdot \mathrm{cm}^{-2}$ as a function of the number of charge-discharge cycles. The experiments were carried out at $5 \mathrm{C}$ in a two-electrode split cell using sodium metal as an anode and $\mathrm{NaI} \cdot 3 \cdot 3 \mathrm{NH}_{3}$ as an electrolyte.

and the effects of cycling, EIS experiments were performed in a two-electrode split cell in the frequency range from $100 \mathrm{kHz}$ to $10 \mathrm{mHz}$ and using a $\pm 10 \mathrm{mV}$ perturbation amplitude at the open-circuit potential of $2.2 \mathrm{~V}$. Figure 8 shows the Nyquist plots obtained before and after 150 charge-discharge cycles. Both plots are characterized in the low-frequency region by a line with a slope much higher than one. This behavior does not seem to be related to a process under diffusion control, modeled by a Warburg element, but to a pseudocapacitive behavior. $^{56,57}$ In the high-frequency region, the plot obtained
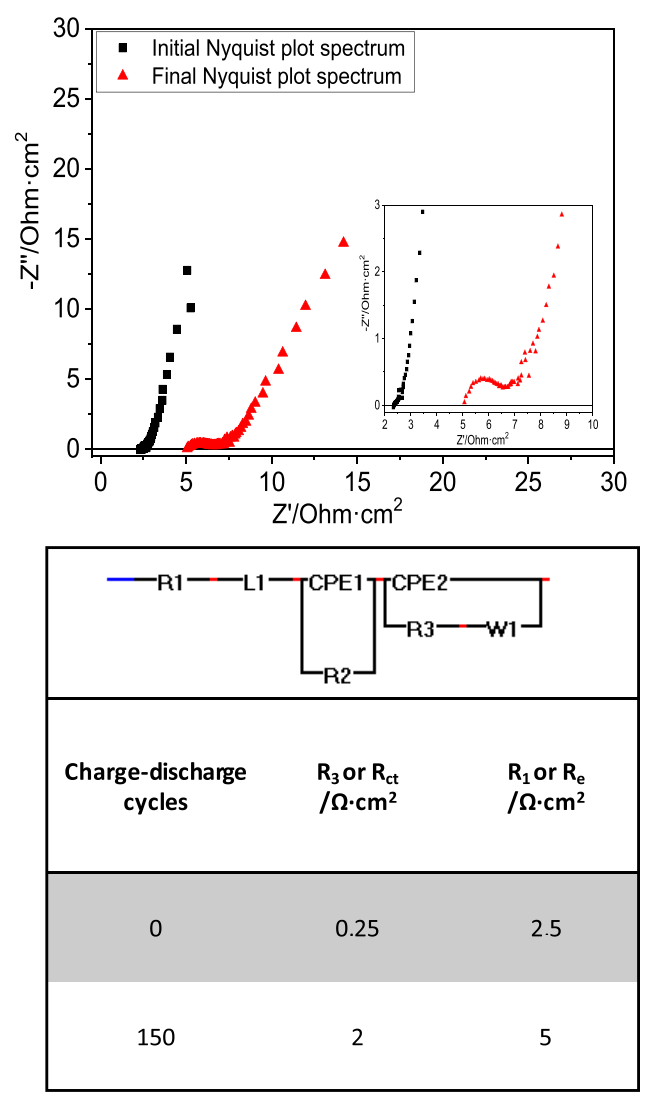

Figure 8. Nyquist plots for a PAQS electrode in $\mathrm{NaI} \cdot 3.3 \mathrm{NH}_{3}$ in the frequency range from $100 \mathrm{kHz}$ to $10 \mathrm{mHz}$ at $2.2 \mathrm{~V}$ vs $\mathrm{Na}^{+} / \mathrm{Na}$, prior (black) and after (red) 150 charge-discharge cycles. The equivalent circuit and the values of the most relevant elements are also included. 
after 150 charge-discharge cycles is characterized by a flattened semicircle, while prior to the charge-discharge cycles, the semicircle is virtually indistinguishable, and the plot is shifted to higher impedance values. The increase in charge-transfer resistance $\left(R_{\mathrm{tc}}\right)$ with the number of cycles suggests that the electrode-electrolyte interphase is being modified, probably due to the presence of irreversibly reduced PAQS and to the induced morphological changes.

It is important to mention that the EIS spectra reported here are significantly different from those obtained for analogous systems with common organic electrolytes. Concretely, the electrolyte resistance value (intersection of the spectrum with the $Z^{\prime}$ axis) and the $R_{\mathrm{ct}}$ value (diameter of the semicircle) are much smaller. ${ }^{32,47,58-60}$ To make a more quantitative assessment, Figure 8 also shows the equivalent electric circuit for the system NalNaI-3.3NH $\mathrm{NH}_{3}$ PAQS obtained using EIS Spectrum Analyzer software. ${ }^{61}$ The circuit is formed by seven elements: inductance $(L)$, which normally appears when the resistance of the electrical connections is higher than the electrolyte resistance; $R_{1}$ corresponding to the resistance of the electrolyte $\left(R_{\mathrm{e}}\right) ; R_{2}$ and $R_{3}$ referring to the charge-transfer resistance $\left(R_{\mathrm{ct}}\right)$ for $\mathrm{Na}$ and PAQS electrodes, respectively; CPE1 and CPE2 or constant phase elements for $\mathrm{Na}$ and PAQS electrodes, respectively, and finally, $\mathrm{W}$, which denotes a Warburg element and represents the $\mathrm{Na}^{+}$diffusion within the cathode. The values of the most relevant elements of the circuit are also gathered in Figure 8. Both $R_{\mathrm{e}}$ and $R_{\mathrm{ct}}$ are significantly lower than those reported for similar systems using organic electrolytes $^{32}$ because of the high sodium concentration and high conductivity of the electrolyte and the good wetting properties of the organic cathode. This once again reveals the excellent physicochemical and electrochemical properties of ammoniate as an electrolyte and the promising behavior of the $\mathrm{NallNaI} \cdot 3.3 \mathrm{NH}_{3} \| \mathrm{PAQS} / \mathrm{NTs} / \mathrm{PTFE}$ system.

\section{CONCLUSIONS}

In this work, the first rechargeable room-temperature sodiummetal battery has been described that uses an ammonia-based liquid electrolyte. PAQS has been chosen as a cathode because it is a well-studied polymer in the context of batteries. It presents a theoretical capacity of $225 \mathrm{~mA} \cdot \mathrm{h} \cdot \mathrm{g}^{-1}$ and its ketone groups are chemically labile, not requiring an extended activation process before starting the charge-discharge cycles. The redox processes are reversible, a behavior that is favored using $\mathrm{NaI}$ ammoniate, characterized by an exceedingly high sodium ion concentration, a high specific conductivity, and good wettability. These relevant properties allow using charge-discharge rates as high as $10.4 \mathrm{~A} \cdot \mathrm{g}_{\mathrm{PAQS}}{ }^{-1}$ without a noticeable depletion of $\mathrm{Na}^{+}$ions inside the porous PAQS structure. The Nyquist plots also reveal a notably smaller charge-transfer resistance in comparison with analogous systems employing organic electrolytes. ${ }^{32,43,55-57}$

A PAQS electrode containing carbon NTs (as a conductive additive) and PTFE (as a binder) can perform at least 300 charge-discharge cycles in $\mathrm{NaI} \cdot 3.3 \mathrm{NH}_{3}$ at $11 \mathrm{C}(2080 \mathrm{~mA}$. $\mathrm{g}_{\mathrm{PAQS}}{ }^{-1}$ ) keeping a Coulombic efficiency close to $100 \%$ for potentials ranging between 1.2 and $2.6 \mathrm{~V}$ vs $\mathrm{Na}^{+} / \mathrm{Na}$. A $4 \mathrm{mg}$. $\mathrm{cm}^{-2}$ PAQS electrode has an initial specific capacity over 200 $\mathrm{mA} \cdot \mathrm{h} \cdot \mathrm{g}_{\mathrm{PAQS}}{ }^{-1}$ even at $62 \mathrm{C}$. It retains over $60 \%$ of its initial specific capacity after 150 cycles at 5C. Importantly, the capacity retention remains close to $80 \%$ after 150 cycles at $5 \mathrm{C}$ when the electrode mass loading increases to $8 \mathrm{mg} \cdot \mathrm{cm}^{-2}$ without a major drop in the capacity. The system NalNaI.
3.3 $\mathrm{NH}_{3} \mid \mathrm{PAQS}$ is characterized by an average specific energy after more than 100 cycles as high as $324 \mathrm{~W} \cdot \mathrm{h} \cdot \mathrm{kg}_{\mathrm{PAQS}}{ }^{-1}$ and a specific power over $3500 \mathrm{~W} \cdot \mathrm{h} \cdot \mathrm{kg}_{\mathrm{PAQS}}{ }^{-1}$. These results are comparable, if not superior, to those reported for analogous systems based on organic electrolytes, which is directly related to the very low charge-transfer resistance found in the ammoniates.

It is also important to mention that a system based on $\mathrm{NaI}$. $3.3 \mathrm{NH}_{3}$ can use sodium metal as an anode at below room and room temperatures, enabling the development of safer devices as ammonia presents limited flammability. Finally, it is worth noting that these liquid electrolytes based on ammonia and simple inorganic salts are significantly more cost-effective than typical organic electrolytes or ionic liquids.

\section{ASSOCIATED CONTENT}

\section{SI Supporting Information}

The Supporting Information is available free of charge at https://pubs.acs.org/doi/10.1021/acsaem.1c00913.

The FESEM micrograph for PAQS powder particles, the potential window for PAQS electrodes, electrochemical behavior optimization for PAQS electrodes, cyclic voltammogram evolution as a function of the number of charge-discharge cycles, the aspect of the split cell elements after electrochemical cycling, and chemical reduction of PAQS and SEM images for a PAQS electrode before and after 300 charge-discharge cycles (PDF)

\section{AUTHOR INFORMATION}

\section{Corresponding Author}

Roberto Gómez - Departament de Química Física i Institut Universitari d'Electroquímica, Universitat d'Alacant, E03080 Alicante, Spain; 이이이.0rg/0000-0002-5231-8032; Email: Roberto.Gomez@ua.es

\section{Authors}

Débora Ruiz-Martínez - Departament de Química Física $i$ Institut Universitari d'Electroquímica, Universitat d'Alacant, E-03080 Alicante, Spain

Teresa Lana-Villarreal - Departament de Química Física $i$ Institut Universitari d'Electroquímica, Universitat d'Alacant, E-03080 Alicante, Spain

Complete contact information is available at:

https://pubs.acs.org/10.1021/acsaem.1c00913

\section{Author Contributions}

This manuscript was written through the contributions of all authors. All authors have given approval to the final version of the manuscript.

\section{Funding}

This work has been developed in the context of project RTI2018-102061-B-I00 financed by FEDER/Ministerio de Ciencia e Innovación-Agencia Estatal de Investigación. The Generalitat Valenciana through project PROMETEO/2020/ 089 is also gratefully acknowledged.

\section{Notes}

The authors declare no competing financial interest.

\section{ACKNOWLEDGMENTS}

A. Kovacs (Broadbit Batteries) is gratefully acknowledged for fruitful discussion. 


\section{ABBREVIATIONS}

$\mathrm{AQ}$ anthraquinone

EIS, electrochemical impedance spectroscopy

NMP, N-methyl-2-pyrrolidone

NTs, carbon NTs

PAQS, poly(anthraquinonyl sulfide)

PTFE, poly(tetrafluoroethylene)

PVDF, poly(vinylidene fluoride)

$\mathrm{SB}$, sodium battery

\section{REFERENCES}

(1) Hwang, J.-Y.; Myung, S.-T.; Sun, Y.-K. Sodium-Ion Batteries: Present and Future. Chem. Soc. Rev. 2017, 46, 3529-3614.

(2) Kimball, S. M. USGS Mineral Commodities Summaries; US Geological Survey, 2016. http://minerals/usgs.gov/minerals/pubs/ mcs/2014/mcs2014.pdf.

(3) Chayambuka, K.; Mulder, G.; Danilov, D. L.; Notten, P. H. L. Sodium-Ion Battery Materials and Electrochemical Properties Reviewed. Adv. Energy Mater. 2018, 8, No. 1800079.

(4) Nayak, P. K.; Yang, L.; Brehm, W.; Adelhelm, P. From LithiumIon to Sodium-Ion Batteries: Advantages, Challenges, and Surprises. Angew. Chem., Int. Ed. 2018, 57, 102-120.

(5) Zheng, X.; Bommier, C.; Luo, W.; Jiang, L.; Hao, Y.; Huang, Y. Sodium Metal Anodes for Room-Temperature Sodium-Ion Batteries: Applications, Challenges and Solutions. Energy Storage Mater. 2019, 16, 6-23.

(6) Eshetu, G. G.; Martinez-Ibañez, M.; Sánchez-Diez, E.; Gracia, I.; Li, C.; Rodriguez-Martinez, L. M.; Rojo, T.; Zhang, H.; Armand, M. Electrolyte Additives for Room-Temperature, Sodium-Based, Rechargeable Batteries. Chem. - Asian J. 2018, 13, 2770-2780.

(7) Kumakura, S.; Tahara, Y.; Kubota, K.; Chihara, K.; Komaba, S. Sodium and Manganese Stoichiometry of P2-Type $\mathrm{Na} 2 / 3 \mathrm{MnO} 2$. Angew. Chem., Int. Ed. 2016, 55, 12760-12763.

(8) Chihara, K.; Kitajou, A.; Gocheva, I. D.; Okada, S.; Jun Ichi, Y. Cathode Properties of Na3M2(PO4) 2F3 $[\mathrm{M}=\mathrm{Ti}, \mathrm{Fe}, \mathrm{V}]$ for Sodium-Ion Batteries. J. Power Sources 2013, 227, 80-85.

(9) Jin, T.; Liu, Y.; Li, Y.; Cao, K.; Wang, X.; Jiao, L. Electrospun $\mathrm{NaVPO} 4 \mathrm{~F} / \mathrm{C}$ Nanofibers as Self-Standing Cathode Material for Ultralong Cycle Life Na-Ion Batteries. Adv. Energy Mater. 2017, 7, No. 1700087

(10) Wang, S.; Zhang, X. B. N-Doped C@Zn3B2O6 as a Low Cost and Environmentally Friendly Anode Material for Na-Ion Batteries: High Performance and New Reaction Mechanism. Adv. Mater. 2019, 31, No. 1805432.

(11) Chandra, M.; Shukla, R.; Rashid, M.; Gupta, A.; Basu, S.; Dhaka, R. S. Synthesis and Physical Properties of $\mathrm{NaxTO}_{2}(\mathrm{~T}=\mathrm{Mn}$, Co) Nanostructures for Cathode Materials in Na-Ion Batteries. Mater. Res. Bull. 2018, 105, 178-183.

(12) Hou, J.; Wang, W.; Feng, P.; Wang, K.; Jiang, K. A Surface Chemistry Assistant Strategy to High Power/Energy Density and Cost-Effective Cathode for Sodium Ion Battery. J. Power Sources 2020, 453, No. 227879.

(13) Kumar, P.; Kheireddine, A.; Nisar, U.; Shakoor, R. A.; Essehli, R.; Amin, R.; Belharouak, I. Na4MnV(PO4)3-RGO as Advanced Cathode for Aqueous and Non-Aqueous Sodium Ion Batteries. J. Power Sources 2019, 429, 149-155.

(14) Zhou, D.; Huang, W.; Lv, X.; Zhao, F. A Novel P2/O3 Biphase $\mathrm{Na} 0.67 \mathrm{Fe} 0.425 \mathrm{Mn} 0.425 \mathrm{Mg} 0.15 \mathrm{O} 2$ as Cathode for High-Performance Sodium-Ion Batteries. J. Power Sources 2019, 421, 147-155.

(15) Liu, S.; Lu, F.; Li, H.; Tian, X.; Wang, H.; Li, J.; Yang, Y. Na2Ru0.8Mn0.2O3: A Novel Cathode Material for Ultrafast Sodium Ion Battery with Large Capacity and Superlong Cycle Life. J. Power Sources 2019, 421, 14-22.

(16) Zhao, Q.; Lu, Y.; Chen, J. Advanced Organic Electrode Materials for Rechargeable Sodium-Ion Batteries. Adv. Energy Mater. 2017, 7, No. 1601792.
(17) Vizintin, A.; Bitenc, J.; Kopač Lautar, A.; Pirnat, K.; Grdadolnik, J.; Stare, J.; Randon-Vitanova, A.; Dominko, R. Probing Electrochemical Reactions in Organic Cathode Materials via in Operando Infrared Spectroscopy. Nat. Commun. 2018, 9, No. 661.

(18) Yuan, C.; Wu, Q.; Shao, Q.; Li, Q.; Gao, B.; Duan, Q.; Wang, $\mathrm{H}$. guo. Free-Standing and Flexible Organic Cathode Based on Aromatic Carbonyl Compound/Carbon Nanotube Composite for Lithium and Sodium Organic Batteries. J. Colloid Interface Sci. 2018, $517,72-79$.

(19) Häupler, B.; Wild, A.; Schubert, U. S. Carbonyls: Powerful Organic Materials for Secondary Batteries. Adv. Energy Mater. 2015, 5, No. 1402034

(20) Miroshnikov, M.; Divya, K. P.; Babu, G.; Meiyazhagan, A.; Reddy Arava, L. M.; Ajayan, P. M.; John, G. Power from Nature: Designing Green Battery Materials from Electroactive Quinone Derivatives and Organic Polymers. J. Mater. Chem. A 2016, 4, 12370-12386.

(21) Gu, S.; Bai, Z.; Majumder, S.; Huang, B.; Chen, G. Conductive Metal-Organic Framework with Redox Metal Center as Cathode for High Rate Performance Lithium Ion Battery. J. Power Sources 2019, $429,22-29$.

(22) Ge, J.; Yi, X.; Fan, L.; Lu, B. An All-Organic Aqueous Potassium Dual-Ion Battery. J. Energy Chem. 2021, 57, 28-33.

(23) Fan, L.; Ma, R.; Zhang, Q.; Jia, X.; Lu, B. Graphite Anode for a Potassium-Ion Battery with Unprecedented Performance. Angew. Chem., Int. Ed. 2019, 58, 10500-10505.

(24) Muench, S.; Wild, A.; Friebe, C.; Häupler, B.; Janoschka, T.; Schubert, U. S. Polymer-Based Organic Batteries. Chem. Rev. 2016, $116,9438-9484$.

(25) Zhu, L.; Liu, J.; Liu, Z.; Xie, L.; Cao, X. Anthraquinones with Ionizable Sodium Sulfonate Groups as Renewable Cathode Materials for Sodium-Ion Batteries. ChemElectroChem 2019, 6, 787-792.

(26) Mu, L.; Lu, Y.; Wu, X.; Ding, Y.; Hu, Y. S.; Li, H.; Chen, L.; Huang, $X$. Anthraquinone Derivative as High-Performance Anode Material for Sodium-Ion Batteries Using Ether-Based Electrolytes. Green Energy Environ. 2018, 3, 63-70.

(27) Gu, S.; Wu, S.; Cao, L.; Li, M.; Qin, N.; Zhu, J.; Wang, Z.; Li, Y.; Li, Z.; Chen, J.; Lu, Z. Tunable Redox Chemistry and Stability of Radical Intermediates in 2D Covalent Organic Frameworks for High Performance Sodium Ion Batteries. J. Am. Chem. Soc. 2019, 141, 9623-9628.

(28) Huang, T.; Lu, D.; Ma, L.; Xi, X.; Liu, R.; Wu, D. A Hit-andRun Strategy towards Perylene Diimide/Reduced Graphene Oxide as High Performance Sodium Ion Battery Cathode. Chem. Eng. J. 2018, $349,66-71$

(29) Li, H.; Tang, M.; Wu, Y.; Chen, Y.; Zhu, S.; Wang, B.; Jiang, C.; Wang, E.; Wang, C. Large $\pi$-Conjugated Porous Frameworks as Cathodes for Sodium-Ion Batteries. J. Phys. Chem. Lett. 2018, 32053211.

(30) Manuel, J.; Zhao, X.; Cho, K.-K.; Kim, J.-K.; Ahn, J.-H. Ultralong Life Organic Sodium Ion Batteries Using a Polyimide/ Multiwalled Carbon Nanotubes Nanocomposite and Gel Polymer Electrolyte. ACS Sustainable Chem. Eng. 2018, 6, 8159-8166.

(31) Zhu, S.; Tang, M.; Wu, Y.; Chen, Y.; Jiang, C.; Xia, C.; Zhuo, S.; Wang, B.; Wang, C. Free-Standing Protective Films for Enhancing the Cyclability of Organic Batteries. Sustainable Energy Fuels 2019, 3, 142-147.

(32) Ai, W.; Zhou, W.; Du, Z.; Sun, C.; Yang, J.; Chen, Y.; Sun, Z.; Feng, S.; Zhao, J.; Dong, X.; Huang, W.; Yu, T. Toward High Energy Organic Cathodes for Li-Ion Batteries: A Case Study of Vat Dye/ Graphene Composites. Adv. Funct. Mater. 2017, 27, No. 1603603.

(33) Lee, J.; Park, M. J. Tattooing Dye as a Green Electrode Material for Lithium Batteries. Adv. Energy Mater. 2017, 7, No. 1602279.

(34) Deng, W.; Liang, X.; Wu, X.; Qian, J.; Cao, Y.; Ai, X.; Feng, J.; Yang, H. A Low Cost, All-Organic Na-Ion Battery Based on Polymeric Cathode and Anode. Sci. Rep. 2013, 3, No. 2671.

(35) Hu, Y.; Gao, Y.; Fan, L.; Zhang, Y.; Wang, B.; Qin, Z.; Zhou, J.; $\mathrm{Lu}, \mathrm{B}$. Electrochemical Study of $\operatorname{Poly}(2,6-$ Anthraquinonyl Sulfide) as 
Cathode for Alkali-Metal-Ion Batteries. Adv. Energy Mater. 2020, 10, No. 2002780

(36) Hu, Y. S.; Lu, Y. The Mystery of Electrolyte Concentration: From Superhigh to Ultralow. ACS Energy Lett. 2020, 5, 3633-3636.

(37) Hosaka, T.; Kubota, K.; Kojima, H.; Komaba, S. Highly Concentrated Electrolyte Solutions for $4 \mathrm{v}$ Class Potassium-Ion Batteries. Chem. Commun. 2018, 54, 8387-8390.

(38) Cao, X.; Jia, H.; Xu, W.; Zhang, J.-G. Review-Localized HighConcentration Electrolytes for Lithium Batteries. J. Electrochem. Soc. 2021, 168, No. 010522.

(39) Badoz-Lambling, J.; Bardin, M.; Bernard, C.; Fahys, B.; Herlem, M.; Thiebault, A.; Robert, G. New Battery Electrolytes for Low and High Temperatures: Liquid and Solid Ammoniates for High Energy Batteries. J. Electrochem. Soc. 1988, 135, 587-591.

(40) Ruiz-Martínez, D.; Gómez, R. The Liquid Ammoniate of Sodium Iodide as an Alternative Electrolyte for Sodium Ion Batteries: The Case of Titanium Dioxide Nanotube Electrodes. Energy Storage Mater. 2019, 22, 424-432.

(41) Ruiz-Martínez, D.; Kovacs, A.; Gómez, R. Development of Novel Inorganic Electrolytes for Room Temperature Rechargeable Sodium Metal Batteries. Energy Environ. Sci. 2017, 10, 1936-1941.

(42) Piaggio, P.; Cuniberti, C.; Dellepiane, G.; Campani, E.; Gorini, G.; Masetti, G.; Novi, M.; Petrillo, G. Vibrational Spectra and Assignment of Poly-(p-Phenylene Sulfide) and Its Oligomers. Spectrochim. Acta, Part A 1989, 45, 347-356.

(43) Gomez, I.; Leonet, O.; Alberto Blazquez, J.; Grande, H. J.; Mecerreyes, D. Poly(Anthraquinonyl Sulfides): High Capacity Redox Polymers for Energy Storage. ACS Macro Lett. 2018, 7, 419-424.

(44) Fang, Y.-B.; Zheng, W.; Li, L.; Yuan, W.-H. An Ultrahigh Rate Ionic Liquid Dual-Ion Battery Based on a Poly(Anthraquinonyl Sulfide) Anode. ACS Appl. Energy Mater. 2020, 3, 12276-12283.

(45) Song, Z.; Zhan, H.; Zhou, Y. Anthraquinone Based Polymer as High Performance Cathode Material for Rechargeable Lithium Batteries. Chem. Commun. 2009, 4, 448-450.

(46) Jian, Z.; Liang, Y.; Rodríguez-Pérez, I. A.; Yao, Y.; Ji, X. Poly(Anthraquinonyl Sulfide) Cathode for Potassium-Ion Batteries. Electrochem. Commun. 2016, 71, 5-8.

(47) Zhao, L.; Guan, Z.; Ullah, Z.; Yu, C.; Song, H.; Chu, R.; Zhang, Y.; Li, W.; Li, Q.; Liu, L. Significantly Stable Organic Cathode for Lithium-Ion Battery Based on Nanoconfined Poly(Anthraquinonyl Sulfide)@MOF-Derived Microporous Carbon. Electrochim. Acta 2020, 335, No. 135681.

(48) Song, Z.; Zhan, H.; Zhou, Y. Anthraquinone Based Polymer as High Performance Cathode Material for Rechargeable Lithium Batteries. Chem. Commun. 2009, 104, 448-450.

(49) Song, Z. P.; Xu, T.; Gordin, M. L.; Jiang, Y. B.; Bae, I. T.; Xiao, Q. F.; Zhan, H.; Liu, J.; Wang, D. H. Polymer Graphene Nanocomposites as Ultrafast-Charge and -Discharge Cathodes for Rechargeable Lithium Batteries. Nano Lett. 2012, 12, 2205-2211.

(50) Liu, Y.; Zhao, F.; Li, J.; Li, Y.; McLeod, J. A.; Liu, L. Influence of Crystal Phase on TiO 2 Nanowire Anodes in Sodium Ion Batteries. J. Mater. Chem. A 2017, 5, 20005-20013.

(51) Xu, W.; Read, A.; Koech, P. K.; Hu, D.; Wang, C.; Xiao, J.; Padmaperuma, A. B.; Graff, G. L.; Liu, J.; Zhang, J. G. Factors Affecting the Battery Performance of Anthraquinone-Based Organic Cathode Materials. J. Mater. Chem. 2012, 22, 4032-4039.

(52) Raj, M. R.; Mangalaraja, R. V.; Contreras, D.; Varaprasad, K.; Reddy, M. V.; Adams, S. Perylenedianhydride-Based Polyimides as Organic Cathodes for Rechargeable Lithium and Sodium Batteries. ACS Appl. Energy Mater. 2019, 3, 240-252.

(53) Yang, G.; Bu, F.; Huang, Y.; Zhang, Y.; Shakir, I.; Xu, Y. In-Situ Growth and Wrapping of Aminoanthraquinone Nanowires within 3D Graphene Framework as High-Performance Foldable Organic Cathode for Lithium Ion Batteries. ChemSusChem 2017, 10, 34193426.

(54) Tang, W.; Liang, R.; Li, D.; Yu, Q.; Hu, J.; Cao, B.; Fan, C. Highly Stable and High Rate-Performance Na-Ion Batteries Using Polyanionic Anthraquinone as the Organic Cathode. ChemSusChem 2019, 12, 2181-2185.
(55) Ahmad, A.; Imani, A.; Mao, L.; Iqbal, R.; Zhang, H.; Ghazi, Z. A.; Ahmad, R.; Khan, A. A.; Xie, L.; Chen, C. M.; Zhang, Z.; Wei, Z. A Bifunctional and Free-Standing Organic Composite Film with High Flexibility and Good Tensile Strength for Tribological and Electrochemical Applications. Adv. Mater. Technol. 2019, 4, No. 1900617.

(56) Song, J.; Bazant, M. Z. Effects of Nanoparticle Geometry and Size Distribution on Diffusion Impedance of Battery Electrodes. J. Electrochem. Soc. 2013, 160, A15-A24.

(57) Bisquert, J.; Garcia-Belmonte, G.; Bueno, P.; Longo, E.; Bulhões, L. O. S. Impedance of Constant Phase Element (CPE)Blocked Diffusion in Film Electrodes. J. Electroanal. Chem. 1998, 452, 229-234.

(58) Ahmad, A.; Meng, Q.; Melhi, S.; Mao, L.; Zhang, M.; Han, B. H.; Lu, K.; Wei, Z. A Hierarchically Porous Hypercrosslinked and Novel Quinone Based Stable Organic Polymer Electrode for LithiumIon Batteries. Electrochim. Acta 2017, 145-152.

(59) Wei, W.; Li, L.; Zhang, L.; Hong, J.; He, G. A BenzoquinoneBased Cathode for Li-Organic Batteries. Mater. Lett. 2018, 213, 126130.

(60) Guo, C.; Zhang, K.; Zhao, Q.; Pei, L.; Chen, J. HighPerformance Sodium Batteries with the 9,10-Anthraquinone/CMK-3 Cathode and a Ether-Based Electrolyte. Chem. Commun. 2015, 51, 10244-10247.

(61) Bondarenko, A. S.; Ragoisha, G. A. EIS Spectrum Analyser, 2013. http://www.abc.chemistry.bsu.by/vi/analyser/program/ program.htm. 